\section{Fouling Mechanism of Micelle EnHANCEd ULTRAFILTRATION WITH SDS SURFACTANT FOR INDIGOZOL DYE REMOVAL}

\author{
Nita Aryanti*, Andya Saraswati, Rangga Pratama Putra, Aininu \\ Nafiunisa, Dyah Hesti Wardhani
}

Department of Chemical Engineering, Faculty of Engineering, Diponegoro University, 50275, Semarang, Indonesia
Article history

Received

23 October 2017

Received in revised form

30 December 2017

Accepted

1 March 2018

Published online

10 May 2018

*Corresponding author nita.aryanti@che.undip.ac.id

\section{Graphical abstract}

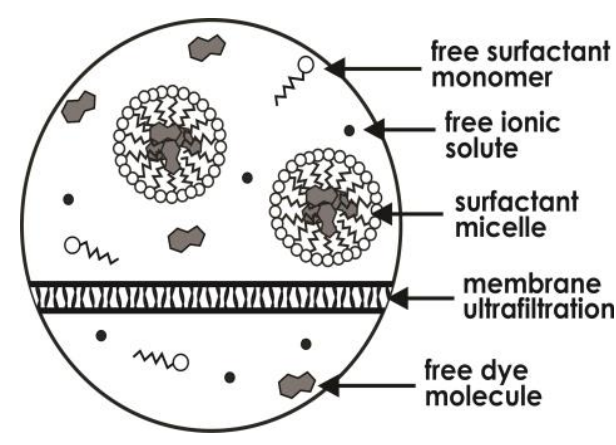

\begin{abstract}
Membrane separation technology was proposed to confront the problem of inorganic dye pollutant treatment such as an indigosol dye. A modified ultrafiltration process known as micellar-enhance ultrafiltration (MEUF), was applied to remove three kinds of indigosol dye (Pink IR, Blve O4B, and vat brown). Surfactant at concentration above $\mathrm{CMC}$ was added to form micelle structure and solubilize the dye molecule in the feed solution. Maximum dye rejection was achieved by the MEUF of all three kinds of indigosol dye. The rejection of indigosol pink IR, blue O4B, and brown VATI were $94,27 \%, 95,49 \%$ and $99,15 \%$, respectively. In this research, it was found that the MEUF system leads to higher membrane flux, compared to the ultrafiltration system as shown in flux profiles. The difference was expected due to different dye molecular structure. Blocking mechanism was predicted by a mathematical model based on Hermia's model and depicted a mechanism of complete blocking on most UF process and cake formation on MEUF process. This result confirmed that the MEUF system certainly retained the dye molecule on membrane separation process. However, a comprehensive study is required to increase the membrane flux.
\end{abstract}

Keywords: Membrane separation, Micellar-enhance ultrafiltration, wastewater, indigo sol dye, blocking mechanism

(C) 2018 Penerbit UTM Press. All rights reserved

\subsection{INTRODUCTION}

Indigosol dye is a reactive synthetic dye commonly used as fabric dye and widely used to produce light and bright color. In Indonesia, indigosol dye is applied as one of the fabric dye for batik industry both on an industrial scale or home industry. The dyeing process produces effluent water containing various types of dyes. The dye pollutant on wastewater needs to be treat before being discharged to the environment. Severe damage on the aquatic environment may happens due to the presence of inorganic or synthetic dyes in wastewater. Many of these dyes are toxic and prone to cause carcinogenic effect. Synthetic dyes originally have a complex molecular structure, making them more stable and very difficult to be degraded [1]. Indigosol dye is a synthetic inorganic reactive dye with highly soluble in water.

Investigation on the removal of inorganic dyes from wastewater has been found in the literature. Major technologies applied to process the dye wastewater were biodegradation [2], adsorption [3, 4], oxidation [5], coagulation-flocculation [6, 7] and membrane separation $[8,9,10,11]$. However, there were some process challenges in inorganic dye pollutant treatment. Conventional biodegradation treatment is not very effective to treat synthetic dye considering its non-biodegradable characteristic. Biological treatment also can barely remove most used dyes, and ineffectively decolorise the 
wastewater effluent. Oxidation methods are only effective to remove organic compounds at very low concentration. Adsorption is very dependable by solution equilibrium and having slow process performance [12].

In order to overcome this challenge, separation using membrane technology is an alternative method to remove synthetic dye from wastewater. Membrane separation technology is known as a technically effective and commercially viable for wastewater treatment [13]. Membrane technology is a pressure driven process with several classifications such as microfiltration (MF), ultrafiltration (UF), nanofiltration (NF), and reverse osmosis (RO) [14]. However, the small particles removal process such as reverse osmosis and nanofiltration were reported having low permeability, higher transmembrane characteristic and required high-pressure condition. This restriction leads to higher working investment and restriction of its extensive use [15]. Therefore, the use of ultrafiltration is expected to provide better membrane performance and low differential pressure.

Nevertheless, conventional ultrafiltration system is limited for removal of some low molecular weight inorganic compound that soluble in water. Indigosol dye molecular weight is slightly below the range of UF membrane molecular weight cut off (400-700 Da). As a consequence, micellar-enhanced ultrafiltration (MEUF) is proposed as a more viable alternative process for effective removal of indigosol dye on wastewater.

MEUF system is a promising physicochemical separation technique, with high effectiveness for removing small molecules $[16,17]$, heavy metals ions $[18,19,20,21]$, and reactive toxic dye $[22,23,24]$ from wastewater. The MEUF technique is performed based on the surfactant characteristic in aqueous solution. At concentration above its critical micellar concentration (CMC), surfactant molecule prone to spontaneously aggregate to form micelles structure [25]. Micelles have large size and hence make them easy to retain together with the pollutant particles bound in its core and allowing permeate with higher purity to be obtained. The mechanism of micellarenhance ultrafiltration is depicted in Figure 1. The MEUF method has the characteristic of low operation pressure, low energy requirement, better-retaining efficiency and simple operating. However, the shortcoming of membrane fouling and concentration polarization was unavoidable [11].

Although many studies of contaminant removal from wastewater have already carried out, not many experimental studies of indigosol dye removal using UF and MEUF membrane separation is reported. It is miserable as indigo sol dye is widely used as dye material on fabric industries. For that reason, this study is focused on the removal efficiency of various indigosol dye (Pink IR, brown VATI and blue O4B) using ultrafiltration and MEUF system. Dye wastewater model solution was used to provide more understanding of the filtration phenomena. The primary objective of this study is to examine different filtration phenomena between ultrafiltration system and MEUF system. The study is conducted by evaluating the flux profile, pollutant concentration on permeate and \% rejection of the membrane. Evaluation of fouling phenomena is also performed by a mathematical model based on Hermia's models, representing different fouling mechanism (complete blocking, standard blocking, intermediate blocking and cake/gel formation).

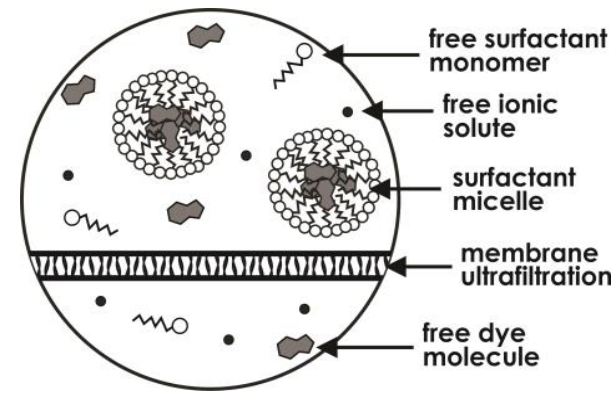

Figure 1 MEUF mechanism of inorganic dye removal

\subsection{METHODOLOGY}

\subsection{Dye Model Solution}

The dye wastewater model solutions were prepared using analytical grade reagents and distilled water as the solvent. Indigosol pink IR, indigo sol brown VATI and indigo sol blue O $4 \mathrm{~B}$ were used as the dye on the wastewater model solution. To make the dye solution, 90 grams of each dye was added to 1 litre of distilled water. The solutions were homogenized using magnetic stirrer without heat treatment. Sodium dodecyl sulphate (SDS) as the surfactant was provided by Sigma-Aldrich. The SDS has molecular weight of $288,372 \mathrm{gr} / \mathrm{mol}$ and the critical micelle concentration of $8,27 \mathrm{mMol}$ [26]. Model of surfactant solution was prepared by adding surfactant at various CMC concentration $(0 ; 1,25 ; 1,5$; and 2 times of CMC). Then the solution was fed into the MEUF system.

\subsection{Ultrafiltration and MEUF System}

The membrane used in this research was flat sheet polyethersulfone (PES) membrane having molecular weight cut off $1 \mathrm{kDa}$ (Sterlitech, USA). The MEUF experiments were conducted at laboratory-made UF membrane cell. Figure 2 presents the MEUF system, which operated in cross-flow mode. The MEUF experiments were carried out at room temperature $\left( \pm 29^{\circ} \mathrm{C}\right)$, and the transmembrane pressure (TMP) was maintained at 1 bar.

Each membrane was compacted before used in the ultrafiltration process. The compaction was conducted by filtering water through the membrane at pressure of 1 bar for 60 minutes. The weight of permeate collected at specific time was calculated 
to get the initial membrane characteristic as pure water flux (Jo). Then, the dye wastewater model solution was feed into the filtration instrument. Permeate fluxes ( $\mathrm{J}$ ) were determined by weighing permeate collected every 5 minutes for 120 minutes.

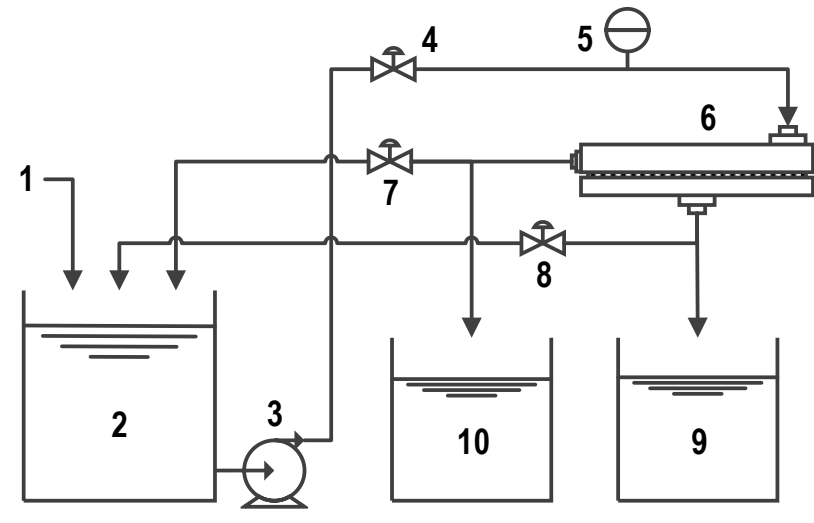

1. Surfactant feed

2. Feed Tank

3. Feed Pump

6. UF Membrane Module

4. Valve

5. Pressure Gauge

7. Retentate Recycle Valve

8. Permeate Recycle Valve

9. Permeate Tank

10. Retentate Tank

Figure 2 Cross flow micellar-enhanced ultrafiltration membrane system

The flux was calculated based on Equation (1).

$$
J=\frac{W}{A x t}
$$

Where $W$ is the weight of permeate, $A$ is the membrane area, and $t$ is the time interval. Ultrafiltration was operated without any addition of surfactant in the feed solution. On the other hand, the micellar-enhanced ultrafiltration was conducted with the addition of surfactant (model surfactant solution). The experiment was a total recycle system where permeate and the retentate were recycled into the feed tank. In each operation, permeate, and retentate were collected and analyzed at the time of 0,60 , and 120 minutes.

\subsection{Analysis of Membrane Rejection}

Ultrafiltration and MEUF performances to remove dye from the wastewater model solution were evaluated by dye rejection. The rejection (R) was calculated for each sample collected at time 0,60 , and 120 minutes. The calculation was carried out according to Equation (2)

$$
\% R=\left(1-\frac{C_{p}}{C_{f}}\right) \times 100 \%
$$

where, $C_{P}$ is permeate concentration and $C_{F}$ is the feed concentration respectively. The concentration of dye was determined using Spectrophotometric UVVis at maximum wavelength by calibration methods.

\subsection{Model of Membrane Fouling Mechanism}

Mathematical models were used to describe the fouling phenomena, based on Hermia's model. Hermia's model comprises four different blocking mechanism models, complete blocking, standar blocking, intermediate blocking, and gel/cake formation. The pore blocking law on filtration process was expressed by equation (3).

$$
\frac{d^{2} t}{d V^{2}}=k\left(\frac{d t}{d V}\right)^{n}
$$

Where $t$ is the filtration time, $V$ is the permeate volume at specific time, $\mathrm{n}$ is a constant to indicate the fouling mechanism. The $n$ value for complete blocking, standard blocking, intermediate blocking, and gel/cake formation is $2,1.5,1$, and 0 , respectively. After taking account of the $n$ value and the condition on each fouling mechanism, the linearised equation according to equation (3) are given in Table 2 [27].

Table 2 Linearisation equation of blocking/fouling models based on Hermia's model

\begin{tabular}{lll}
\hline $\begin{array}{c}\text { Model of Blocking } \\
\text { Mechanism }\end{array}$ & $\begin{array}{c}\text { Linearize } \\
\text { Equation }\end{array}$ & Physical Concept \\
\hline Complete Blocking & $\ln J=\ln J_{0}-K_{c} t$ & $\begin{array}{l}\text { Formation of } \\
\text { surface deposit }\end{array}$ \\
Standard Blocking & $\frac{1}{\sqrt{J}}=\frac{1}{\sqrt{J_{0}}}+K_{s} t$ & $\begin{array}{l}\text { Pore blocking and } \\
\text { surface deposit }\end{array}$ \\
Intermediate & $\frac{1}{J}=\frac{1}{J_{0}}+K_{i} t$ & Pore constriction \\
Blocking & $\frac{1}{J^{2}}=\frac{1}{J_{0}^{2}}+K_{e f} t$ & Pore blocking \\
$\begin{array}{l}\text { Gel/Cake } \\
\text { Formattion }\end{array}$ & & \\
\hline
\end{tabular}

\subsection{RESULTS AND DISCUSSION}

\subsection{Permeate Flux Profile of UF and MEUF System}

Various kinds of indigosol dyes were separated from the wastewater model solution using ultrafiltration and MEUF. Ultrafiltration process was conducted without the presence of surfactant, while MEUF was carried out by the presence of surfactant on various concentration. Flux profiles at a various time for filtration of indigosol VAT brown, indigosol Pink IR, and Indigosol blue were shown in Figure 3. 
(A)

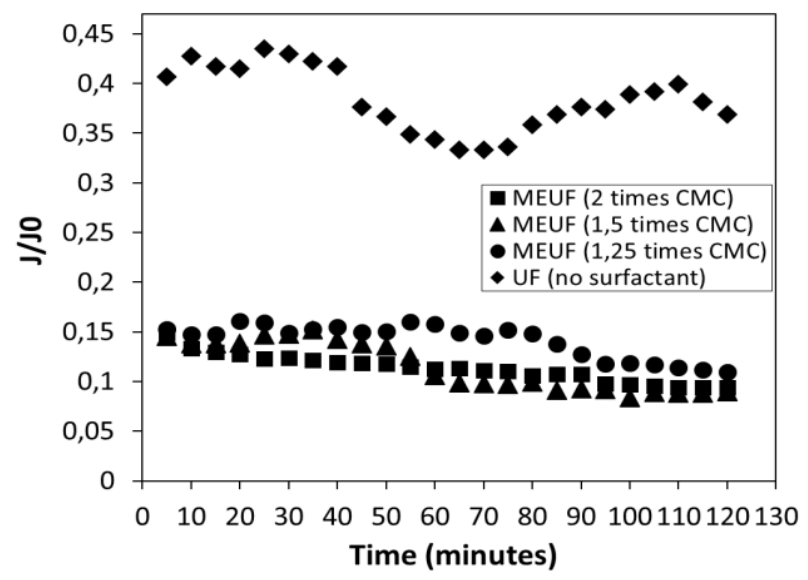

(B)

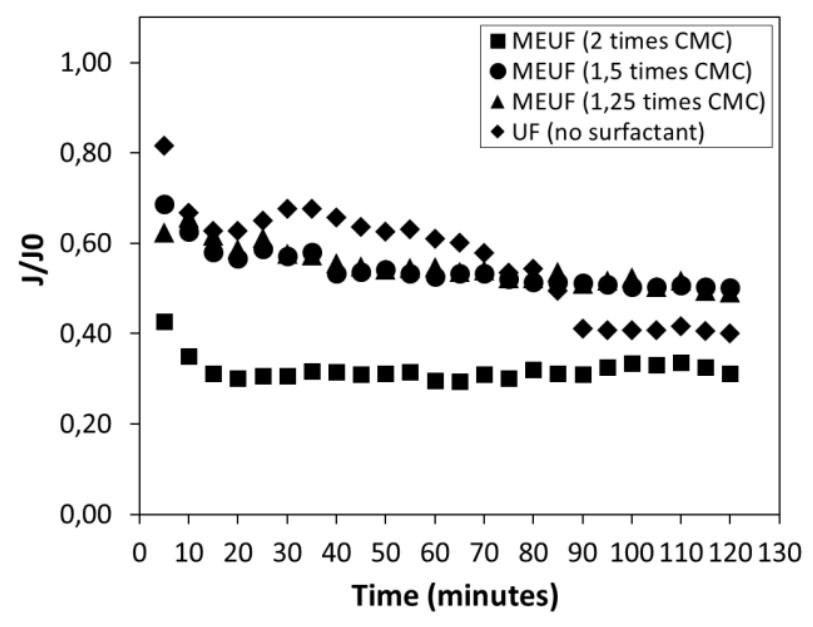

(C)

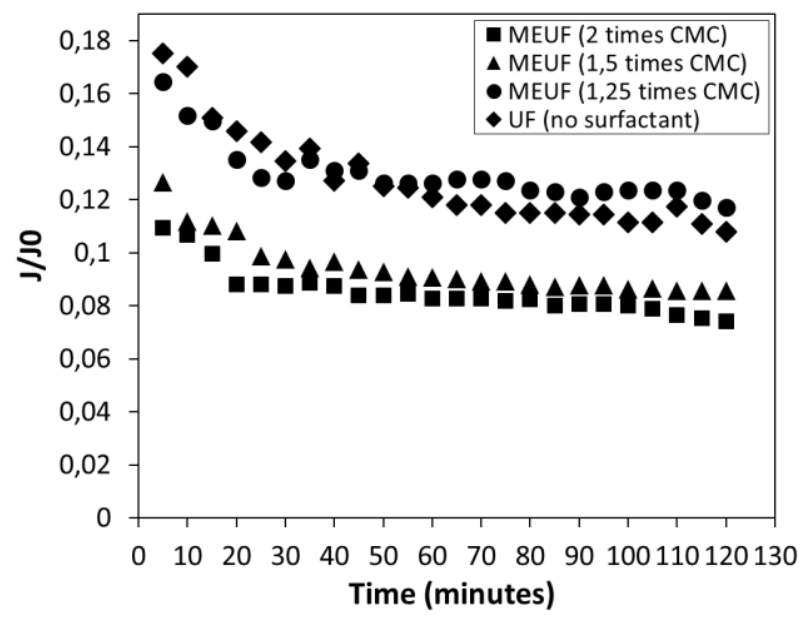

Figure 3 Flux profile of indigosol dye filtration by ultrafiltration and MEUF for: (A) Indigo sol pink IR, (B) Indigo sol blue O4B and (C) Indigo sol brown VATl

Indigosol dye is a leuco ester reactive dye having a specific ionic structure of ion $\mathrm{Na}^{+}$[31]. Each indigosol dye has their own specific ion placement resulting to the difference of colour appearance. In this study, three kinds of indigosol dyes were used, and molecular structure of each indigosol dyes are presented in Figure 3.<smiles>Cc1cc(Cl)cc2sc(-c3sc4cc(Cl)cc(C)c4c3OS(=O)(=O)[O-])c(OS([NH3+])(=O)=O)c12</smiles>

(A) Indigosol Pink IR<smiles>O=S(=O)([O-])c1c(-c2c(S(=O)(=O)[O-])c3ccccc3n2[18OH])[nH]c2ccccc12</smiles>

(B) Indigosol blue $\bigcirc 4 \mathrm{~B}$<smiles>O=S(=O)([O-])Oc1c(-c2sc3ccc4ccccc4c3c2OS(=O)(=O)[O-])sc2ccc3ccccc3c12</smiles>

(C) Indigosol brown VATI

Figure 4 Molecular structure of indigo sol dye

Figure 4 shows that indigosol pink IR have a pair of $\mathrm{Na}^{+}$ion on the same side, as indigosol blue and indigosol VAT brown have the ion pairing on the opposite side. The different of ion deposition between the indigosol dyes affecting its interaction with the surfactant molecules. Adding of surfactant to an aqueous solution at concentration above its $\mathrm{CMC}$ generates the formation of surfactant micelle. In general, the internal core of the micelle is the hydrophobic region, having the ability to solubilise hydrophobic or less polar molecule. In contrast, the external polar or charged layer of micelle has the more hydrophilic characteristic. Based on the ion disposition, the ionic interaction between indigosol pink and surfactant molecule mainly occur only on 
one side and leaving the other side of dye molecule to have the more hydrophobic characteristic. The hydrophobic side has a tendency to attach to the membrane because the PES membrane is partly hydrophobic. This result in the accumulation of dye molecule on the membrane surface and lower the flux value compared to those process without surfactant addition. Similar solubilisation mechanism of hydrophobic and hydrophilic substances by surfactant micelle was also reported in the previous study for removal of emerging contaminants [25, 32] and fractionated natural organic matter [33].

As for indigosol blue and indigosol VAT brown, the flux of wastewater with surfactant addition is similar to the flux of dye only wastewater. It is expected that the surfactant-dye interaction takes place more thoroughly on each opposite side of the dye molecule. Emerging thorough hydrophilic external layer covering the dye molecule. This layer prohibits the micelle molecule attached to the membrane surface. In addition, a cross flow system of the filtration process inducing a vertical flow of solution through the membrane surface and generate a concentration gradient on the membrane film and diffuse the micelle back to the feed bulk.

\subsection{Dye Molecule Rejection}

Membrane performance is determined by its ability to retain a particular component expressed as percent of rejection. Membrane rejection is an important parameter to present the selectivity of the membrane. Membrane selectivity is used to measure the membrane ability to retain or let pass a particular species. Membrane selectivity depends on the interfacial interaction between membrane surface to the species that pass through it, the size of the species and the membrane pore size. Substances having molecular weight higher than membrane pore size is retained on the membrane surface as retentate, whereas the smaller-molecular-weighted species will pass through the membrane as permeate. In this experiment, permeate is expected to be water with relatively low impurities (dye molecules) content. Table 1 shows the dye concentration on permeate after filtration.

Table 1 Concentration of dye impurities on the permeate after membrane separation

\begin{tabular}{cccc}
\hline $\begin{array}{c}\text { Surfactant } \\
\text { Concentration }\end{array}$ & \multicolumn{3}{c}{ Dye Concentration on Permeate } \\
\cline { 2 - 4 } & $\begin{array}{c}\text { Indigosol } \\
\text { Blue O4B }\end{array}$ & $\begin{array}{c}\text { Indigosol } \\
\text { Pink IR }\end{array}$ & $\begin{array}{c}\text { Indigosol } \\
\text { Brown } \\
\text { VAT1 }\end{array}$ \\
\hline $0 \mathrm{cmc}$ & 4651,29 & 5186 & 2653,14 \\
$1,25 \mathrm{cmc}$ & 4297,18 & 5188,5 & 1553,14 \\
$1,5 \mathrm{cmc}$ & 4090,12 & 5172,25 & 1062,94 \\
$2 \mathrm{cmc}$ & 4057,18 & 5157,25 & 766,86 \\
\hline
\end{tabular}

Based on Table 1, the dye concentration of the ultrafiltration system is higher than the MEUF. This corresponds to more dye impurities transfer into permeate on the ultrafiltration system whether caused by direct pass through the membrane film or convective transfer of solute particles. The addition of surfactant into the polluted aqueous wastewater resulting in the lower of impurities concentration on permeate. The surfactant was added at concentration higher than CMC, where the surfactant molecule aggregates and forming micelles. The surfactant used in this study is SDS, an anionic surfactant having specific negative charge on the aqueous solution. The dye impurities bind with the negatively charged micelles of SDS surfactant and make it bigger than the membrane pore. As a result, it can be retained by the ultrafiltration membrane. The use of SDS surfactant to form micelles on the wastewater treatment by MEUF has already investigated. The successful result is also reported by the previous study for removal of cadmium ions [28], chromium ions [34], boron ion [17] and zinc ions [35].

As seen in Table 1, the indigosol VAT brown permeate have lower concentration of dye impurities compared with other indigosol dye. Based on the molecular structure of each indigosol dye used in this experiment, the indigosol VAT brown has a bigger molecular structure with 4 hexagonal aromatic group. While the indigosol pink IR and indigosol blue only have 2 hexagonal aromatic group. This more prominent structure of indigosol brown allows molecules to retain easily on the membrane than other smaller molecules. Moreover, aggregation of surfactant to form micelles and solubilise dye molecule on the micelles structure making it to have bigger molar volume.

The pollutant concentration on permeate also affects the membrane rejection. Permeate with lower impurities concentration specify a better membrane rejection. The membrane rejection of various indigosol filtration under ultrafiltration and MEUF system is exhibited in Figure 5 which have conformity with the trend of impurities concentration on permeate.

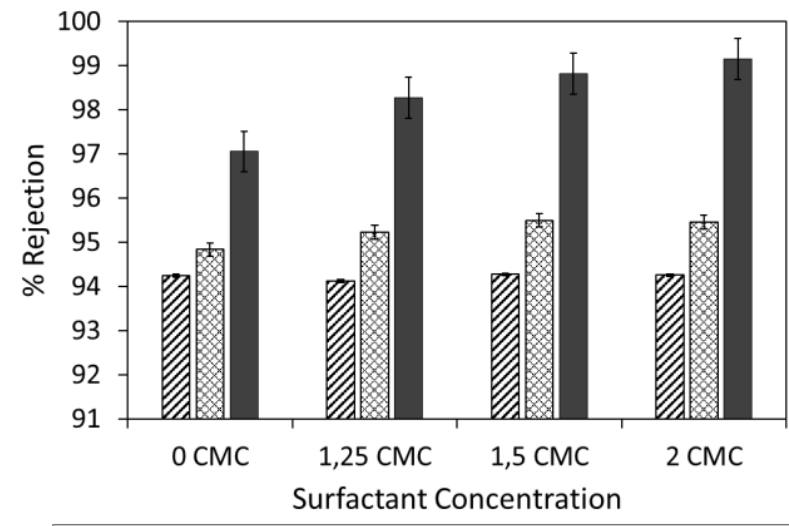

Ⓘndigo sol pink IR $\mathrm{Q}$ Indigo sol blue O4B Indigo sol brown VAT1

Figure 5 Rejection of indigo sol dye at various $C M C,(A)$ Indigo sol pink IR, (B) Indigo sol blue O4B and (C) Indigo sol brown VATl 


\subsection{Model of Blocking Mechanism}

Mathematical model can be useful to accurately predict the fouling phenomena on the membrane filtration process. Blocking mechanism of indigosol dye during ultrafiltration and MEUF was studied by application of Hermia's mathematical model. Hermia model provides a comprehensive fouling prediction models, well equipped with four different fouling mechanisms [33]. The experimental filtration data is fit to the empirical fouling models by Hermia to identify well suited fouling mechanisms. Previous study reported a well fitted result of Hermia's model with the experimental data for removal of polysaccharides [36], organic pollutant [27], and remazol dye [37] from wastewater.

Table 2 Mathematical model parameter of UF and MEUF blocking phenomena on indigo sol dye removal

\begin{tabular}{|c|c|c|c|c|c|c|c|c|c|}
\hline \multirow{2}{*}{$\begin{array}{l}\text { Indigo } \\
\text { sol dye }\end{array}$} & \multirow{2}{*}{$\begin{array}{l}\text { Filtration } \\
\text { system }\end{array}$} & \multicolumn{2}{|c|}{$\begin{array}{c}\text { Complete Blocking } \\
(n=2)\end{array}$} & \multicolumn{2}{|c|}{$\begin{array}{l}\text { Intermediate } \\
\text { Blocking }(n=1)\end{array}$} & \multicolumn{2}{|c|}{$\begin{array}{c}\text { Standard Blocking } \\
(n=3 / 2)\end{array}$} & \multicolumn{2}{|c|}{$\begin{array}{l}\text { Cake Formation } \\
\qquad(n=0)\end{array}$} \\
\hline & & $\mathbf{R}^{2}$ & $\mathrm{Kc}$ & $\mathbf{R}^{2}$ & $\mathrm{Ki}$ & $\mathbf{R}^{2}$ & Ks & $\mathbf{R}^{2}$ & Kfc \\
\hline \multirow{2}{*}{ Pink IR } & Ultrafiltration & 0,8863 & $-0,0024$ & 0,8784 & 0,0014 & 0,8826 & 0,0009 & 0,8681 & 0,0017 \\
\hline & MEUF & 0,8589 & $-0,0057$ & 0,8691 & 0,0026 & 0,8646 & 0,0019 & 0,8748 & 0,0023 \\
\hline \multirow{2}{*}{ Blue O4B } & Ultrafiltration & 0,8645 & $-0,0057$ & 0,8463 & 0,0026 & 0,8567 & 0,0019 & 0,821 & 0,0024 \\
\hline & MEUF & 0,8812 & $-0,002$ & 0,8972 & 0,0008 & 0,8896 & 0,0006 & 0,9099 & 0,0006 \\
\hline \multirow{2}{*}{$\begin{array}{l}\text { Brown } \\
\text { VAT1 }\end{array}$} & Ultrafiltration & 0,8741 & $-0,0028$ & 0,8722 & 0,0017 & 0,8555 & 0,0012 & 0,8998 & 0,0017 \\
\hline & MEUF & 0,8096 & $-0,002$ & 0,808 & 0,0012 & 0,7886 & 0,0009 & 0,8436 & 0,0011 \\
\hline
\end{tabular}

Table 2 shows fitting experimental data and the degree of model fitness (represent by $\mathrm{R}^{2}$ ) based on Hermia's model. The value of corresponding correlation $\left(R^{2}\right)$ was simply used to determine the fitted blocking mechanism rationally. The befitting experimental data and the degree of model fitness (represent by $\mathrm{R}^{2}$ ) based on Hermia's model. The value of corresponding correlation $\left(R^{2}\right)$ was merely used to determine the fitted blocking mechanism rationally. The complete blocking mechanism fit the experimental data for ultrafiltration of indigosol blue and indigosol pink IR. While ultrafiltration of indigosol VAT brown is fit to the cake formation mechanism. The micellar-enhanced ultrafiltration of all indigosol dye used in this study also shows a fitting to cake formation mechanism.

Complete blocking is the blocking mechanism resulting a reduction of open pores without deposition of foulant particles on the membrane surface. This blocking occurs when the foulant particle size is similar with the membrane pore size. Cake formation is the most severe blocking mechanism on the membrane filtration. This blocking occurs when the foulant particles deposition already block the membrane pore and initiate cake formation [38, 39].

As explained before, the molecular structure of indigosol blue and pink IR is smaller than indigo sol vat brown. Hence, it is possible if there is a different blocking mechanism between indigosol blue and pink IR with the indigosol vat brown. Indigosol vat brown has a more significant molecular structure, allowing it to deposit on the membrane surface and initiate cake formation highly. The filtration of indigosol dye by MEUF system is fitted to the cake formation mechanism. Theoretically, the dyesurfactant micelle has a bigger molecular structure compared with the monomer structure of surfactant only or dye only. The micelle will deposit on the membrane surface, causing fouling over the time of filtration, and induce membrane pore blocking.

\subsection{CONCLUSION}

In this study, micellar-enhance ultrafiltration system is aimed to remove reactive indigosol dye from wastewater. The process was compared to the common ultrafiltration system. Results show better dye pollutant rejection by the addition of surfactant. The formation of surfactant micelle is expected to help the retaining of dye molecule. However, the addition of surfactant in the MEUF system also lowered the permeate flux. In addition, different profiles of membrane flux between each indigosol dye were shown. The different molecular structure of each indigosol dye is presumed as the primary factor of different flux and rejection profile. Fouling/blocking mechanism of UF and MEUF process to remove indigo sol dye is predicted by mathematical model based on Hermia's model. Based on the model, fouling mechanism was complete blocking and gel/cake formation. Further experimental work to study indigosol dye removal by membrane separation is indeed still required. Indigosol dye is an easily oxidize reactive dye. Hence, the effect of oxidation support factor also needs to be considered in the ultrafiltration and MEUF process.

\section{Acknowledgement}

This research is supported by Diponegoro University through International Research Publication Grant year of 2017 . 


\section{References}

[1] Mukimin, A., Vistanty, H., Zen, N., Purwanto, A., Wicaksono, K. A. 2018. Performance of BioequalizationElectrocatalytic Integrated Method for Pollutants Removal of Hand-drawn Batik Wastewater. Journal of Water Process Engineering. 21: 77-83. Doi.org/10.1016/j.jwpe.2017.12.004.

[2] Pearce, C. I., Lloyd, J. R. and Guthrie, J. T. 2003. The Removal of Colour from Textile Wastewater Using Whole Bacterial Cells: A Review. Dyes Pigments. 58: 179-196. Doi.org/10.1016/S0143-7208(03)00064-0.

[3] Han, H., Wei, W., Jiang, Z., Lu, J., Zhu, J., Xie, J. 2016. Removal of Cationic Dyes from Aqueous Solution by Adsorption onto Hydrophobic/Hydrophilic Silica Aerogel. Colloids Surf. A: Physicochem. Eng. Aspects. 509: 539-549. Doi.org/10.1016/j.colsurfa.2016.09.056.

[4] Isah, U. A., Abdulraheem, G., Bala, S., Muhammad, S. Abdullahi, M. 2015. Kinetics Equilibrium and Thermodynamics Studies of C. I. Reactive Blue 19 Dye Adsorption on Coconut Shell Based Activated Carbon. Int. Biodeterior. Biodegrad. 102: 265-273.

Doi.org/10.1016/j.ibiod.2015.04.006.

[5] Nidheesh, P. V., Zhou, M., Oturan, M. A. 2018. An Overview on the Removal of Synthetic Dyes from Water by Electrochemical Advanced Oxidation Processes. Chemosphere. In Press, Accepted Manuscript.

Doi.org/10.1016/j.chemosphere.2017.12.195.

[6] Liang, C., Sun, S., Li, F., Ong, Y., Chung, T. 2014. Treatment of Highly Concentrated Wastewater Containing Multiple Synthetic Dyes by a Combined Process of Coagulation/Flocculation and Nanofiltration. Journal of Membrane Science. 469: 306-315.

Doi.org/10.1016/j.memsci.2014.06.057.

[7] Yeap, K. L., Teng, T. T., Poh, B. T., Morad, N., Lee, K. E. 2014. Preparation and Characterization of Coagulation/Flocculation Behavior of a Novel InorganicOrganic Hybrid Polymer for Reactive and Disperse Dyes Removal. Chem. Eng. J. 243: 305-314.

Doi.org/10.1016/j.cej.2014.01.004.

[8] Zaghbani, N., Hafiane, A., Dhahbi, M. 2008. Removal of Safranin T from Wastewater Using Micellar Enhanced Ultrafiltration. Desalination. 222: 348-356.

Doi:10.1016/j.desal.2007.01.148.

[9] Luo, F., Zeng, G-M., Huang, J-H., Zhang, C., Fang, Y-Y., Qu, Y-H., Li, X., Lin, D., Zhou, C. F. 2010. Effect of Groups Difference in Surfactant on Solubilization of Aqueous Phenol using MEUF. Journal of Hazardous Materials. 173: 455-461. Doi.org/10.1016/j.jhazmat.2009.08.106

[10] Koseoglu-Imer, D. Y. 2013. The Determination of Performances of Polysulfone (PS) Ultrafiltration Membranes Fabricated at Different Evaporation Temperatures for the Pretreatment of Textile Wastewater. Desalination. 316: 110-119. Doi.org/10.1016/j.desal.2013.02.011.

[11] Huang, J. H., Zhou, C. F., Zeng, G. M., Li, X., Huang, H. J., Niu, J., Li, F., Shi, L. J., He, S. B. 2012. Studies on the Solubilization of Aqueous Methylene Blue in Surfactant using MEUF. Separation and Purification Technology. 98: 497-502.

Doi.org/10.1016/j.seppur.2012.08.012.

[12] Li, X., Zeng, G. M., Huang, J. H., Zhang, C., Fang, Y. Y., Qu, Y. H., Luo, F., Lin, D., Liu, H. L. 2009. Recovery and Reuse Of Surfactant SDS from a MEUF Retentate Containing Cd2+ or $\mathrm{Zn} 2+$ by Ultrafiltration. Journal of Membrane Science. 337: $92-97$ doi.org/10.1016/j.seppur.2012.08.012.

[13] Liu, M., Chen, Q., Lu, K., Huang, W., Lü, Z., Zhou, C., Yu, S., Gao, C. 2017. High Efficient Removal of Dyes from Aqueous Solution Through Nanofiltration Using Diethanolamine Modified Polyamide Thin-Film Composite
Membrane. Separation and Purification Technology. 173: 135-143. doi.org/10.1016/j.seppur.2016.09.023.

[14] Víctor-Ortega, M. D., Martins, R. C., Gando-Ferreira, L. M., Quinta-Ferreira, R. M. 2017. Recovery of Phenolic Compounds from Wastewaters through Micellar Enhanced Ultrafiltration. Colloids and Surfaces A. 531: 1824. Dx.doi.org/10.1016/j.colsurfa.2017.07.080.

[15] El-Abbassi, A., Khayet, M., Hafidi, A. 2011. Micellar Enhanced Ultrafiltration Process for the Treatment of Olive Mill. Wastewater Water Research. 45: 4522-4530.

Doi:10.1016/j.watres.2011.05.044.

[16] Huang, J., Qia, F., Zeng, G., Shi, L., Li, X., Gu, Y., Shi, Y. 2017. Repeating Recovery and Reuse of SDS Micelles from MEUF Retentate Containing Cd2+ by Acidification UF. Colloids and Surfaces A: Physicochem. Eng. Aspects. 520: 361-368. Dx.doi.org/10.1016/j.colsurfa.2017.02.001.

[17] Tortora, F., Innocenzi, V., Celso, G. M-d., Vegliò, F., Capocelli, M., Piemonte, V., Prisciandaro M. 2018. Application of Micellar-enhanced Ultrafiltration in the PreTreatment of Seawater for Boron Removal. Desalination. 428: $21-28$. Doi.org/10.1016/j.desal.2017.11.016.

[18] Fang, Y. Y., Zeng, G. M., Huang, J. H., Ke, X. U. 2006. Removal of Metal Ions and Dissolved Organic Compounds in the Aqueous Solution via Micellar Enhanced Ultrafiltration. Environ. Sci. 27: 641-646.

[19] labal, J., Kim, H. J., Yang, J. S., Baek, K., Yang, K. W. 2007. Removal of Arsenic from Groundwater by MicellarEnhanced Ultrafiltration (MEUF). Chemosphere. 66: 970976. Doi.org/10.1016/j.chemosphere.2006.06.005.

[20] Zhen, Z., Zeng, G. M., Huang, J. H., Ke, X. U., Fang, Y. Y., Yu, H. 2009. Removal of Zinc lons from Aqueous Solution Using Micellar-enhanced Ultrafiltration at Low Surfactant Concentrations. Water. S. A. 33: 129-136. DOI: 10.4314/wsa.v33i1.48787.

[21] Huang, J., Lei, P., Zeng, G., Xue, L., Yong, Z., Liu, L., Fei, L., Qi, C. 2014. Evaluation of Micellar-enhanced Ultrafiltration for Removing Methylene Blue and Cadmium Ion Simultaneously with Mixed Surfactants. Separation and Purification Technology. 125: 83-89. DOI:10.1016/j.seppur.2014.01.020.

[22] Ahmad, A. L., Puasa, S. W., Zulkali, M. M. D. 2006. Micellarenhanced Ultrafiltration for Removal of Reactive Dyes from an Aqueous Solution. Desalination. 191: 153-161. Doi:10.1016/j.desal.2005.07.022.

[23] Purkait, M. K., DasGupta, S., De, S. 2006. Micellarenhanced Ultrafiltration of Eosin Dye Using Hexadecyl Pyridinium Chloride. J. Hazard. Mater. B. 136:972. doi.org/10.1016/j.jhazmat.2006.01.040.

[24] Bielska, M., Sobczyńska, A., Prochaska, K. 2009. Dyesurfactant Interaction in Aqueous Solutions. Dyes and Pigments. 80(2): 201-205. Doi:10.1016/j.dyepig.2008.05.009

[25] Acero, J. L., Benitez, F. J., Real, F. J., Teva, F. 2017. Removal of Emerging Contaminants from Secondary Effluents by Micellar-enhanced Ultrafiltration. Separation and Purification Technology. 181: 123-131. Dx.doi.org/10.1016/j.seppur.2017.03.021 .

[26] Bade, R., Lee, S. H. 2011. A Review of Studies on Micellar Enhanced Ultrafiltration for Heavy Metals Removal from Wastewater. Journal of Water Sustainability. 1 (1): 85-102. DOI:10.11912/jws.1.1.85-102.

[27] Zhang, W., Liang, W., Huang, G., Wei, J., Ding, L., Jaffrin, M. Y. 2015. Studies of Membrane Fouling Mechanisms Involved in the Micellar-enhanced Ultrafiltration Using Blocking Models. RSC Advance. 5(60): 48484-48491. DOI: 10.1039/C5RA06063J.

[28] Li, X., Zeng, G. M., Huang, J. H., Zhang, D. M., Shi, L. J., He, S. B., Ruan, M. 2011. Simultaneous Removal of Cadmium Ions and Phenol with MEUF using SDS and Mixed Surfactants. Desalination. 276: 136-141. 
Doi:10.1016/j.desal.2011.03.041

[29] Fang, Y. Y., Zeng, G. M., Huang, J. H., Liu, J. X., Xu, X. M., $X U, K$. , and QU, Y. H. 2008. Micellar-enhanced Ultrafiltration of Cadmium lons with Anionic-nonionic Surfactants. Journal of Membrane Science. 320: 514-519. Doi:10.1016/j.memsci.2008.04.042.

[30] Vinder, A., and Simonič, M. 2012. Removal of AOX from Waste Water with Mixed Surfactants by MEUF. Desalination. 289: 51-57. Doi:10.1016/j.desal.2012.01.007.

[31] Chattopadhyay, S. N., Pan, N. C., Roy, A. K., and Khan, A. 2009. Dyeing of Jute Fabric Using Indigosol Dyes. Journal of Natural Fibers. 6: 98-107. DOI: 10.1080/15440470802703596.

[32] Exall, K., Balakrishnan, V. K., Toito, J., and McFadyen, R. 2013. Impact of Selected Wastewater Constituents on the Removal of Sulfonamide Antibiotics via Ultrafiltration and Micellar Enhanced Ultrafiltration. Sci. Total Environ. 461462: 371-376. Dx.doi.org/10.1016/j.scitotenv.2013.04.057.

[33] Chang, E.-E., Yang, S.-Y., Huang, C.-P., Liang, C.-H., and Chiang, P.-C. 2011. Assessing the Fouling Mechanisms of High-Pressure Nanofiltration Membrane using the Modified Hermia Model and the Resistance-in-Series Model. Separation and Purification Technology. 79: 329-336. Doi:10.1016/j.seppur.2011.03.017.

[34] Aoudia, M. Allal, N., Diennet, A., and Toumi, L. 2003. Dynamic Micellar Enhanced Ultrafiltration: Use of Anionic (SDS)-nonionic (NPE) System to Remove $\mathrm{Cr}^{3+}$ at Low
Surfactant Concentration. Journal of Membrane Science. 217: 181-192.

Doi.org/10.1016/S0376-7388(03)00128-5

[35] Zhang, Z., Zeng, G. M., Huang, J. H., Fang, Y. Y., Xu, K., Qu, Y. H., Yang, C., and Li, J. B. 2009. Removal of Zinc lons from Aqueous Solution Using Micellar-Enhanced Ultrafiltration at Low Surfactant Concentrations. Water S. A. 33(1): 129-136. DOI: 10.4314/wsa.v33il.48787.

[36] Nataraj, S., Schomacker, R., Kraume, M., Mishra, I. M., and Drews, A. 2008. Analyses of Polysaccharide Fouling Mechanisms during Crossflow Membrane Filtration. Journal of Membrane Science. 308: 152-161.

Doi.org/10.1016/j.memsci.2007.09.060.

[37] Aryanti, N., Sandria, F. K. I., and Wardhani, D. H. 2017. Blocking Mechanism of Ultrafiltration and MicellarEnhanced Ultrafiltration Membrane for Dye Removal from Model Waste Water. Advanced Science Letters. 23: 25982600.

DOI: 10.1166 /asl.2017.8730.

[38] Grzegorzek, M., and Majewska-Nowak, K. 2018. The Use of Micellar-enhanced Ultrafiltration (MEUF) for Fluoride Removal from Aqueous Solutions. Separation and Purification Technology. 195: 1-11. Doi.org/10.1016/j.seppur.2017.11.022.

[39] Sarkar, B. DasGupta, S., De, S. 2009. Application of External Electric Field to Enhance the Permeate Flux During Micellar Enhanced Ultrafiltration. Separation and Purification Technology. 66: 263-272. Doi:10.1016/j.seppur.2009.01.003 